\title{
A review of fixation disparity ${ }^{+}$
}

\author{
E Chetty*, S Jackson*, C Mitton* and TK Phillips* \\ Department of Optometry, University of Johannesburg, PO Box 524. Auckland Park, 2006 South \\ Africa
}

\section{< stevejacksonster@gmail.com >}

Optometrists tend to break up the visual system into various fragments. They test each fragment and try to come up with cures for, or at least effective relief from, many types of symptoms. For example, optometrists may take a concept such as fixation disparity, test for it, and based on how ever they understand the results, may or may not prescribe accordingly. This is also true for other aspects of the visual system such as lag and lead of accommodation and phorias. This review is going to take the subject of fixation disparity, analyze it and try to come to an understanding of how one actually knows that problems exist, if they exist at all.

Fixation disparity was defined by Ogle, Martens and Dyer ${ }^{1}$ in the late 1940 's. According to Palmer $e l^{2}$ it was Hofmann and Bielschowsky, followed by Ames and Gliddon, who were the first to experimentally demonstrate this phenomenon. Previously referred to as 'posture', 'slip' or 'shift', Ogle et al defined fixation disparity as "the apparent displacement of the uniocularly observed details of targets whose other details are fused binocularly"1. This occurs when the eyes are not exactly aligned to view an object in visual space. The retinal images do not produce bifoveal stimulation, however, they do still fall within Panum's fusional areas and therefore clear, single binocular vision is still perceived ${ }^{1}$.

There are two main theories for the explanation of fixation disparity ${ }^{3,4}$. The first theory introduced by Ogle is that fixation disparity is a result of stress on the vergence system. As the magnitude of the stress increases, the misalignment also increases. The vergence response is unable to keep up with the demand placed on the vergence system. According to this theory, it is appropriate to prescribe in order to try to 'compensate' for the fixation disparity and remove this unnecessary 'stress' on the visual system. The second theory, introduced by Schor $^{3}$, is that fixation disparity is a purposeful steady state error providing a stimulus to vergence innervations. According to this theory, fixation disparity is a normal physiological occurrence and it is generally not necessary to compensate for it. The measurements may differ from person to person according to the neural makeup of each individual's vergence system.

London $^{5}$ discusses two approaches when it comes to measuring fixation disparity; the sensory approach and the motor based approach. The sensory approach, introduced by Haase ${ }^{5}$, attempts to examine the state of the visual system without any extra fusional demand. The approach more common to us is the motor approach which is used to determine Ogle's forced vergence curves ${ }^{1}$, and is what our discussions are based on here. Testing for fixation disparity with the motor approach is also known as the forced vergence approach ${ }^{5}$. The clinician changes the vergence demand by known amounts of prism and measures the effect on fixation disparity. The motor approach can be further divided into subjective and objective measurements. ${ }^{1,6}$ When fixation disparity is measured objectively ${ }^{1,7}$ it is not a measure of the absolute vergence angle of the eyes, but rather a measure of the relative shift in position that occurs in the one eye. Thus the actual rotation of the eye is measured when changes in the apparent displacement of a monocularly perceived object occur in conjunction

\footnotetext{
${ }^{+}$This review is based on work done as part of the requirements of the course Binocular Vision B at the University of Johannesburg.

${ }^{*}$ Fourth year students registered for the degree BOptom

Received 19 September 2007; revised version accepted 1 November 2007
} 
with a change in convergence. This can be done using the scleral search coil technique ${ }^{7}$. The subject wears annular contact lenses which allow the examiner to detect the horizontal as well as vertical eye movements. This technique is less commonly used in a clinical setting and is more for research purposes. Significant differences have been found between objective and subjective measures of fixation disparity ${ }^{6,8,9}$. Both Kertesz ${ }^{8}$ and Remole ${ }^{9}$ found the objective measurement to be much larger than the subjective measurement. Fogt and Jones $^{6}$ found that differences occurred in the slope of the curve. The objectively obtained fixation disparities had a much larger slope when compared to the subjectively obtained measurements. When an alteration in the retinal correspondence occurs it changes the direction of nonius lines as it shifts Panum's area into the direction of the fusion lock target. This means that the measurement of subjective fixation disparity will tend to underestimate the actual objective fixation disparity by the amount of shift in retinal correspondence ${ }^{6}$.

The most common tests used clinically to measure subjective fixation disparity are the Sheedy disparometer, the Wesson card, the Woolf card on which the Wesson card is based, and the Saladin near point balance test ${ }^{4,5}$. Some of the traditional subjective tests, such as the Mallett $\mathrm{Box}^{4,10}$, are unable to measure fixation disparity. They can indicate the direction of the fixation disparity but actually measure only the associated phoria.

The concept of forced vergence curves ${ }^{1,3,4,5,11}$ was originally designed by Ogle. He found that when constructing forced vergence curves, although the individual values varied significantly, most subjects fell into four categories depending on how they tolerated the prism ${ }^{1}$. The basic diagnostic components of a fixation disparity curve are the $y$-intercept, which represents the actual fixation disparity in minutes of arc, and the $x$ intercept which represents the associated phoria or the amount of prism which results in zero fixation disparity. Base-out prism makes the subject converge, forcing vergence away from the point of fixation and resulting in an increased exo fixation disparity. Base-in prism forces divergence which should increase eso fixation disparity ${ }^{4}$. When prism is added accommodation remains at the target plane.

Type I fixation disparity curves have a sigmoid shape. Ogle found that the majority of subjects fell into this category and it is thought of as a reference curve. These subjects adapt equally to base-in and base-out prism. Fixation disparity increases more rapidly the nearer you get to the limits of fusion in both directions. Type II curves are missing the lower portion of the sigmoid shape. There is little or no increased exo fixation disparity with base-out prism. Type III curves are similar to Type II curves but it is the reaction to forced divergence which is atypical. These subjects adapt very well to base-in prism and there is little or no increase in eso fixation disparity. Type IV fixation disparity curves represent an unstable binocular system which absorbs both base-in and base-out prism with little change in fixation disparity. This curve is rare and usually found only with abnormal binocularity such as strabismus ${ }^{4}$.

Lenses can also be used to produce these curves ${ }^{1,4}$. The lenses cause a change in accommodation which results in a change in vergence innervation. Positive lenses usually result in increased exo fixation disparity while negative lenses increase eso fixation disparity. The curve type gives the practitioner an indication of how the subject adapts to lenses and prism, and the effect they may have on the individual's visual system. The slope of the curve ${ }^{4}$ shows the rate at which fixation disparity changes in response to a change in vergence demand. A steeper slope indicates that the visual system does not readily adapt to prism while a flatter slope would indicate a visual system able to adapt well.

The curves are supposed to provide a guideline to the practitioner as to how to go about treating the patient. Treatment or therapy ${ }^{4,5}$ is aimed at placing the visual system in the flattest area of the curve or flattening the slope of the curve thereby making the system more adaptable. Prisms, lenses and vision therapy are used.

In 1949 Ogle et al $^{11}$ suggested that, in the most level part of the curve, the direction of the fixation disparity corresponded with the direction of the phoria. Most studies after this ${ }^{1,2,12}$ have found little correlation between dissociated heterophorias and fixation disparity. Palmer and von Noorden $(1978)^{2}$ suggested that fixation disparity is not necessarily caused by a heterophoria and similarly a heterophoria is not sustained by fixation disparity as was previously believed.

Fixation disparity is measured under the following conditions: A subject views a target through prisms or lenses, and polarizing filters. When measuring fixation disparity it is important to maintain binocular vision 
except for the two dichoptically viewed reference lines ${ }^{13}$, these reference lines are usually nonius or vernier lines because they prove to measure the fixation disparity more accurately. Ogle et al ${ }^{1}$ reported that if one was to measure the angle of fixation disparity the target should be constructed so that one of the monocularly seen test lines can be displaced relative to the other. A fixation disparity target must also always present with a central or paracentral fusion lock, which is seen by both eyes.

Various studies have been done where two types of fixation disparity tests have been compared. When Goss and Patel ${ }^{14}$ compared the Sheedy disparometer with the Wesson card, they found that the results differed significantly and they concluded that it would be unwise to compare results of one test to normative values of the other test. The most conspicuous difference was that type I fixation disparity curves were more common with the Wesson card and type II curves proved to be more common with the disparometer. Further it was found that with the Wesson card the $y$-intercepts tended to be more exo and the $x$-intercepts were shifted more towards the base-in side of the graph ${ }^{14}$.

In study done by Ngan et $\mathrm{al}^{13}$ the Wesson card was compared with the Saladin fixation disparity test. Once again the results showed that the Wesson card gave curves shifted towards base-in on the $x$-axis and shifted in the exo direction on the $y$-axis. They then concluded that the Saladin fixation disparity curves are more closely related to the disparometer findings but unfortunately no tests have been done to date to compare the two. Fixation disparity can also be measured using a Brock Posture Board in the form of a two target test. A fusion lock must be drawn on the board and the patient, wearing anaglyphs, moves the penlight until they see it aligned with the cross. As far as we know, little or no research has been conducted to compare the results obtained with the Brock Posture Board method to the results of any other tests.

There are many different parameters which influence the subjective measurement of fixation disparity in a clinical setting. Even as early as 1949 Ogle et $a l^{11}$ noted that their measurements varied "for no obvious reason". How do factors such as the length and separation of the nonius lines, the size and position of the fusion lock, as well as test distance and the effects of accommodation and vergence, affect the measurements obtained with these tests?

Significant differences were found when the Sheedy disparometer fixation disparity was measured in and out of the phoropter in a study done by Frantz and Scharre ${ }^{15}$. Possible reasons for the differences between these two measurements could be due to proximal convergence. Measurements through the phoropter may cause greater proximal convergence thus giving greater eso-associated phorias. Another factor is that behind the phoropter the subject has to maintain an erect head posture, whereas when the test is done through a trial frame a more natural posture is obtained and there is nothing blocking the peripheral field ${ }^{15}$.

Nonius bias is a phenomenon experienced when, instead of dichoptic presentation of nonius lines, two physically aligned nonius lines are seen by both eyes, or just by the right or left eye. The nonius bias is the adjustment made by the observer in order to perceive the physically aligned lines as aligned ${ }^{16,17}$. Binocular nonius bias is the offset between the two lines when both lines are seen by both eyes. Monocular nonius bias is the offset when only one eye sees both lines. Jaschinski et $a l^{16}$ found that the binocular nonius bias could be predicted by finding the mean of the monocular nonius bias of the right and left eye. This goes along with the concept that the mean of the two monocular visual directions will give rise to the binocular visual direction ${ }^{3}$.

Nonius bias appears to increase with an increased vertical separation of the nonius lines and decrease with decreased length of the lines ${ }^{16,17}$. A larger vertical offset of the lines also makes it more difficult to accurately judge any misalignment. It could be possible to reduce the effects of this bias on fixation disparity measurement by reducing the vertical separation of the nonius lines in our clinical tests. In another study Ukwade ${ }^{18}$ found fixation disparity to be invariant with change in nonius line length and separation, however, his sample size was very small and perhaps not a true indication of the effects.

Jaschinski et al ${ }^{16}$ found that there was a correlation between the binocular nonius bias measured and the fixation disparity measurement. They suggested that perhaps some of the variability in fixation disparity measurements could be explained by the presence of the nonius bias. This 'individually stable parameter, ${ }^{19}$, could be removed by calculating a patient's fixation disparity relative to their binocular nonius bias. 
Another factor involving nonius lines was investigated by $\operatorname{Larson}^{20}$ in 1982 . He explored the idea that alignment of the nonius lines can be perceived over a range of disparities and that the range depended on how the patient approached alignment. Perceived nonius alignment is limited by perceived alignment and perceived misalignment. Larson found that the width of the range was larger when moving from perceived alignment to the first perceived misalignment, and smaller when approaching first perceived alignment from perceived misalignment. Thus our measurements may vary depending on our instructions to the patient and how they approach perceived alignment. The issue of patient instructions was investigated in a recent study performed by Karania and Evans ${ }^{10}$. They found that patients are more likely to exhibit fixation disparity when specific questions are asked instead of simply using the standardized method of questioning.

Fixation disparity measurements also vary with the size and positioning of the fusion lock. Ukwade ${ }^{18}$ found that a central fusion lock gives a smaller fixation disparity measurement than a peripheral one. He also noted that the inclusion of a central lock reduces the variability of the measurements. In a study done by Ogle et al ${ }^{11}$ it was found that the fixation disparity changes quite notably if the fusion lock is pushed into the periphery. The measurements will increase rapidly due to Panum's fusional area, which increases with increased retinal eccentricity ${ }^{1,3}$ and this will cause the subject to present with a larger than normal fixation disparity while still maintaining fusion ${ }^{11}$. This may lead to results which are less stable than results obtained when using a central fusion lock. A peripheral lock requires the use of larger Panum's areas resulting in less accurate fixation. There is also the concept of 'capture of visual direction' discussed by Erklens and van $\mathrm{EE}^{21}$. The reliability of nonius lines as an indicator of eye position has been questioned a few times. 'Capture of visual direction' ${ }^{21}$ indicates that the perceived direction of nonius lines does not necessarily correlate to the visual direction of each eye, as the perceived directions of monocular objects are influenced by nearby binocularly seen objects. In other words the perceived direction of nonius lines dichoptically, in the presence of a fusion lock, may not be an accurate indication of the eye position. This is reinforced by the differences found between subjective and objective measurements of fixation disparity ${ }^{6,8,9}$.

When measuring fixation disparity, as with most things involving the visual system, it is extremely difficult to isolate the effects of a single system as there are so many components contributing to the final outcome. It is well established that there is a synkinesis between the accommodation and vergence systems, accommodation being driven primarily by blur and vergence driven primarily by disparity of retinal images ${ }^{22}$. Changing the accommodative stimulus to the eye will result in a change in accommodative convergence. The resulting change in vergence will influence the fixation disparity measurement.

Semmlow and Hung ${ }^{23}$ conducted a study where they attempted to eliminate accommodation and vergence interactions during the measurement of fixation disparity. The use of a pinhole gives the patient a large depth of focus, removing the blur stimulus to accommodation. The fixation disparity measurement taken through a pinhole therefore should not provide a stimulus to accommodation and therefore should remove the effect of accommodative convergence on the result. Under these open loop conditions they found that the fixation disparity measured was considerably less than that measured under closed loop conditions. Because the only known difference between the two measurements was the influence of accommodative convergence, they concluded that a large portion of fixation disparity is probably due to accommodative interactions.

Jaschinski has conducted many studies on the effects of test distance and dark vergence on fixation disparity ${ }^{19,24,25}$. Dark vergence, also known as tonic vergence, is the resting position of the vergence system in the absence of any visual stimuli. The average resting position for vergence is at about $1 \mathrm{~m}$. He found that fixation disparity tended towards the locus of the dark vergence ${ }^{19,25}$. For a target near $1 \mathrm{~m}$ the mean fixation disparity was zero. As the target was moved closer the fixation disparity became more exo, and as it was moved further than $1 \mathrm{~m}$ the measurements became more eso ${ }^{19}$. This suggests that the most accurate vergence is found near the dark vergence.

Jaschinski suggested that between $26-56 \%$ of inter-subject variability in fixation disparity measurement could be a result of dark vergence ${ }^{25}$. Accommodation accounts for only $20 \%$ of inter subject variation at near ${ }^{19}$. Subjects with a further dark vergence need to converge and accommodate more strongly for a near target and 
exhibit a more eso fixation disparity than someone with a closer dark vergence. He found that the position of the dark vergence did not differ much from the position of the dark focus (the resting position of accommodation) and that the AC/A ratio did not seem to play a role in the measurement of fixation disparity ${ }^{19}$.

Fixation disparity is thought to be related to asthenopic symptoms. Researchers such as Jaschinski ${ }^{24,25}$ feel that tests should be done according to the viewing conditions the patient uses on a day to day basis. Most clinical tests are done under good lighting and contrast, conditions which do not necessarily truly reflect the conditions of everyday tasks.

In 1997 Jaschinski $^{24}$ compared the results of classical forced vergence fixation disparity measurements (using prism) to measurements taken at different viewing distances providing the same vergence angle as the prism. On average he found that the measurements became more exo as the target was moved closer to the patient. He also found that the prism dependant forced vergence curve was 2.7 times steeper than the distance dependant curve. This indicates that prism induces larger fixation disparity than a viewing distance inducing the same viewing angle. This can be explained by accommodation. Accommodation remains constant in the forced vergence curve as the target distance is fixed, but as the target is brought closer accommodation must increase and this causes an increased eso or lower exo fixation disparity than induced by base-out prism.

Fixation disparity has been found to become more exo with increasing target blur and reduced levels of illumination ${ }^{25,26}$. Yekta et $a l^{26}$ found that after reading for $30 \mathrm{~min}$ in reduced illumination, subjects had fixation disparity measurements that were more exo than before the reading session. They also found an increase in exo fixation disparity after $30 \mathrm{~min}$ reading at a very close working distance $(20 \mathrm{~cm})$. This result goes along with the findings of Jaschinski ${ }^{19,24,25}$. The increased exo fixation disparity seems to be associated with visual fatigue. Liversedge $e t a l^{27}$ found that while reading many subjects displayed an exo fixation disparity and Cornell et $a l^{28}$, using objective measurements, found fixation disparities to be common even in subjects considered to have normal binocular vision.

After taking a brief look at the various issues related to fixation disparity, it leaves one pondering about how much we as optometrists actually know about it. Fixation disparity varies under all types of conditions and is not always repeatable from one test procedure to another. When the measurements vary the resulting forced vergence curves will vary and eventually the diagnosis made will depend on how the measurements were obtained. Even with much theory on how to prescribe using forced vergence fixation disparity curves, no strong research exists showing that it actually works. Fixation disparity is a complex and poorly understood phenomenon. We do not feel that it should be used in isolation as an indicator of visual problems although it is useful in conjunction with other tests to get a complete diagnosis and treatment plan. As is true for many other areas of optometry, evidence of the clinical significance of fixation disparity is still limited. So to answer the question of how one actually knows that problems exist in the visual system is not that simple. Perhaps optometry's approach of breaking up the visual system into fragments and examining them is too simplistic. Optometry is often clinically successful, but we should not always believe that our success is based upon our complete understanding of the problems that exist.

\section{References}

1. Ogle KN, Martens TG, Dyer JA. Oculomotor imbalance in binocular vision and fixation disparity. Philadelphia: Lea and Febiger 1967 pp 4-5,12-16, 30-38, 40-52, 75-89.

2. Palmer EA, von Noorden GK. The relationship between fixation disparity and heterophoria. American Journal of Ophthalmology 197886 172-175.

3. Schor CM, Ciuffreda KJ. Vergence eye movements: Basic and clinical aspects. Boston: Butterworth 1983 pp 201202, 467, 472-476.

4. Despotidis N, Petito T. Fixation disparity: clinical implications and utilization. Journal of the American Optometric Association 199162 923-933.

5. London R, Crelier RS. Fixation disparity analysis: sensory and motor approaches. Optometry 200677 590-608.

6. Fogt N, Jones R. Comparison of fixation disparities obtained by objective and subjective methods. Vision 
Research 199738 411-421.

7. Fogt N, Jones R. Comparison of the monocular occlusion and a direct method for objective measurement of fixation disparity. Optometry and Vision Science 1997 74 43-50.

8. Kertesz AE. Comparison of simultaneously obtained objective and subjective measurements of fixation disparity. American Journal of Optometry and Physiological Optics 198764 734-738.

9. Remole A, Code SM, Matyas CE, McLeod MA, White DJ. Objective measurement of binocular fixation misalignment. American Journal of Optometry and Physiological Optics 1986 63 631-638.

10. Karania R, Evans B. The Mallet fixation disparity test: influence of test instructions and relationship with symptoms. Ophthalmic and Physiological Optics 200626 507-522.

11. Jampolsky A, Flom BC, Fried AN. Fixation disparity in relation to heterophoria. American Journal of Ophthalmology 195743 97-106.

12. Ogle KN, Mussey F, Prangen A. Fixation disparity and the fusional processes in binocular single vision. American Journal of Ophthalmology 194932 1069-1087.

13. Ngan J, Goss DA, Despirito J. Comparison of fixation disparity curve parameters obtained with Wesson and Saladin fixation disparity cards. Optometry and Vision Science 200582 69-74.

14. Goss DA, Patel J. Comparison of fixation disparity curve variables measured with the Sheedy disparometer and Wesson fixation disparity card. Optometry and Vision Science 199572 580-588.

15. Frantz KA, Scharre JE. Comparison of disparometer fixation disparity curves as measured with and without the phoropter. Optometry and Vision Science 199067 117-122.

16. Jaschinski W, Bröde P, Griefahn B. Fixation disparity and nonius bias. Vision Research 199939 669-677.

17. Jaschinski W, Kloke W, Jainta S, Buchholz J. Horizontal fixation disparity measures with nonius lines. Optometry and Vision Science 200582 988-999.

18. Ukwade MT. Effects of nonius line and fusion lock parameters on fixation disparity. Optometry and Vision Science 200077 309-320.

19. Jaschinski W. Fixation disparity and accommodation for stimuli closer and more distant than oculomotor tonic positions. Vision Research 200141 923-933.

20. Larson WL. Uncertainty in the measurement of fixation disparity due to zones of perceived nonius alignment. Graefe's Archive of Clinical and Experimental Ophthalmology 1982219 233-235.

21. Erkelens C, van EE R. Capture of visual direction: an unexpected phenomenon in binocular vision. Vision Research 199737 1193-1196.

22. Daum KM, McCormack GL. Fusion and binocularity. In: Benjamin WJ, ed. Borish's clinical refraction Missouri: Butterworth-Heinemann, 2006 pp163-164.

23. Semmlow JL, Hung G. Accommodation and the fusional components of fixation disparity. Investigative Ophthalmology and Visual Science 197918 1082-1086.

24. Jaschinski W. Fixation disparity and accommodation as a function of viewing distance and prism load. Ophthalmic and Physiological Optics 199717 324-339.

25. Jaschinski-Kruza W. Dark vergence in relation to fixation disparity at different luminance and blur levels. Vision Research 199434 1197-1204.

26. Yekta AA, Pickwell LD, Jenkins TCA. Binocular vision without visual stress. Optometry and Vision Science 198966 815-817.

27. Liversedge SP, White SJ, Findlay JM, Rayner K. Binocular coordination of eye movements during reading. Vision Research 200646 2363-2374.

28. Cornell ED, Macdougall HG, Predebon J, Curthoys IS. Errors of binocular fixation are common in normal subjects during natural conditions. Optometry and Vision Science 200380 764- 771. 